\title{
What Are Ethics in Doctoral Supervision, and How Do They Matter? Doctoral Students' Perspective
}

\section{Löfström, Erika}

2020-06-06

Löfström , E \& Pyhältö , K 2020 , ' What Are Ethics in Doctoral Supervision, and How Do They Matter? Doctoral Students' Perspective ' , Scandinavian Journal of Educational Research , vol. 64 , no. 4 , pp. 535-550 . https://doi.org/10.1080/00313831.2019.1595711

http://hdl.handle.net/10138/319558

https://doi.org/10.1080/00313831.2019.1595711

unspecified

acceptedVersion

Downloaded from Helda, University of Helsinki institutional repository.

This is an electronic reprint of the original article.

This reprint may differ from the original in pagination and typographic detail.

Please cite the original version. 
To cite: Löfström, E. \& Pyhältö, K. (In press). What are ethics in doctoral supervision, and how do they matter? Doctoral students' perspective. Scandinavian Journal of Educational Research. DOI: 10.1080/00313831.2019.1595711

\title{
What are ethics in doctoral supervision, and how do they matter? Doctoral students' perspective
}

\begin{abstract}
The purpose of this study was to examine ethics in doctoral supervision, and to analyse whether ethical issues in doctoral supervision relate to doctoral experience, and if they do, how. It focused on doctoral students and explored the relationships between ethical issues in doctoral supervision and attrition intentions, research engagement, satisfaction with supervision and with doctoral studies, and burnout. The study provides a tool for analyzing ethical issues in doctoral supervision. The respondents were 236 doctoral students in behavioral sciences. Ethics in supervision predicted both positive outcome variables (engagement, satisfaction with doctoral studies and supervision) and negative ones (burnout, attrition intentions). Autonomy and beneficence were essential components for engagement, while fidelity, justice, and non-maleficence were vital for satisfaction.
\end{abstract}

Keywords: Doctoral studies; supervision ethics; ethical principles; student experiences

\section{Introduction}

Doctoral students' experiences have gained increased attention in research on doctoral education in the Nordic countries (e.g. Pyhältö, Vekkaila \& Keskinen, 2015; Godskesen \& Kobayashi, 2016; Kobayashi et al., 2017; Cornér, Löfström \& Pyhältö, 2017). At the same time, it is known that supervision, both the quality and quantity of it, is a key regulator of the doctoral experience (Pyhältö, Vekkaila, \& Keskinen, 2012). Hence, this study focuses on the intersection of the doctoral experience of supervisory practice through the lens of ethics.

Halse and Bansel (2012) argue for the necessity of contextualizing doctoral supervision as ethical relations among multiple parties and practices, including supervision, pedagogy and experience. Yet, there is little research on supervision analysed through an ethics framework. Studies in this domain have conceptualized supervision pedagogy as ethical practice (Halse \& Malfroy, 2010) and as mentoring for integrity (Gray \& Jordan, 2012); and identified ethical problems and challenges in supervision (Goodyear, Crego, \& Johnston, 1992; Mahmud \& Bretag, 2013; Löfström \& Pyhältö, 
2012; 2014; 2015; 2017; Whitley \& Page, 2015). In addition, studies have explored doctoral students' traumatizing experiences of supervision (Lee \& Williams, 1999; Truong, 2010), and highlighted challenges and problems in supervision. These and other studies (e.g. Lee, 2008) also bring forth tensions between dependence and independence, and the issue of confounded relationships, which in other studies (Goodyear, Crego, \& Johnston, 1992; Löfström \& Pyhältö, 2012) have been conceptualized through a pronounced ethical lens.

Based on the set of previous qualitative studies (Löfström \& Pyhältö, 2012; 2014; 2015; 2017) we set out to identify if supervision ethics matter, and if they do, what are the implications of ethical problems in supervision for doctoral students, and we created a tool for this purpose.

\section{Supervision as pedagogical practice}

We highlight two features of supervision as pedagogical practice that are relevant in the context of ethics. First, developing as researcher involves socialisation into the research community (Neumann, Parry, \& Becher, 2002; Parry, 2007). In all their activities, the members of the scholarly community, including supervisors in particular, convey images of what it means to be an academic, what are the explicit and implicit standards and practices as well as accepted behaviors in the scholarly community. Research ethics and supervision ethics are not one and the same thing even though they intertwine through the many practices embedded in researcher communities. In research ethics, focus in on the processes of conducting research, while in supervision ethics focus is on supervision as pedagogical transaction and interaction.

Doctoral students identify the prevailing norms through observation and participation in the community (Anderson \& Louis, 1994). Much of the practices in doctoral supervision evolve around research practices, and supervisors do indeed associate 'good research' with ethics (Kiley \& Mullins, 2005). Doctoral students develop an identity as novice researchers learning how research is conducted and how it informs the various activities taking place in the scholarly community. As far as ethical norms are concerned, supervisors and senior colleagues play a vital role as ethical examples for their students (Alfredo \& Hart, 2011; Gray \& Jordan, 2012).

Doctoral students perceive their scholarly community, its boundaries and roles differently, and they position themselves differently within the community. This may have consequences also for ethical conduct. Research has shown that ethical misconduct was most prevalent among research workers who were not integrated into the scholarly community (True, Alexander, \& Richman, 2011). This 
may be problematic, as research shows that even as much as a third of the doctoral students may feel isolated from their community or experience that their relation to the research community is problematic (cf. Pyhältö, Stubb \& Lonka, 2009). Of course, this does not imply that doctoral students who do not feel connected to their respective research communities engage in misconduct, but serves to demonstrate that there may be implications of weak connectedness to research community. Simultaneously, participation in a research community has been identified as a key learning experience in the doctoral journey (Vekkaila et al., 2012). The study shows the importance for doctoral students to experience belonging and feeling accepted into a research community. The opposite includes alienating experiences of poor treatment, sense of insecurity, frustration and loneliness.

Second, supervision is activity between individuals and within groups in the scholarly community (Pearson \& Brew, 2002; Pyhältö et al, 2009; Baker \& Lattuca, 2010; Stubb, 2012). Supervision is materialized in the relationships, interactions and transactions among individuals and groups of individuals. The role that these play in the doctoral students' experience is evident: Doctoral students emphasise social support and interaction with researchers among the key resources in their doctoral studies (Gardner, 2007; Protivnak \& Foss, 2009). The wider supervision resource includes peer groups, research seminars, research teams and units, networks and doctoral schools, and also they are agents of supervision (Baker \& Lattuca, 2010). They, too, may shape doctoral students' experiences of the nature of relationships pertaining to supervision.

\section{Conceptualizing Ethics in Doctoral Supervision}

Prior studies in U.S. and Australian contexts have identified various forms of ethical problems in supervision, including issues around incompetent and inadequate supervision, supervisor abandonment, intrusion of supervisor views, abusive and exploitative supervision, bullying, confounded or dual relationships, encouragement to commit fraud, and authorship issues (Goodyear, Crego, \& Johnston, 1992; Mahmud \& Bretag, 2013). We have attempted a theorization of ethics in supervision, and in light of the prior studies and our own qualitative research with both doctoral students and supervisors (Löfström \& Pyhältö, 2012; 2014; 2015; 2017) in which we have identified experiences of breaches of ethical principles, we assessed that principle ethics may be a way forward to provide an overarching structure for the ways in which ethics emerge in doctoral supervision.

Ethics is comprised of general, normative principles concerning what is acceptable and what is not. Academic integrity, in turn, involves honest and ethical everyday practices in the contexts in which 
academic staff and early career researchers engage in inquiry (Jordan, 2013). While ethics refers to expectations regarding moral positions, integrity refers to acting upon those moral positions. In doctoral supervision, integrity and ethics are often intertwined through moral decision-making in settings permeated by the normative and tacit practices of research communities (cf. Löfström \& Pyhältö, 2012; 2015). We use the concept supervision ethics rather than supervision integrity, or supervision morals, as we are essentially probing "standards of moral behavior, expressed with reference to ethical theory" (cf., Jordan, 2013, 252). As we are interested in doctoral students' experiences of the ethical aspects of supervision, we will not analyse the practical application of ethical principles as attributes of supervisors' moral. Rather than viewing supervision as moral activity, per se, we view the learning-to-do-research and the supervision of related processes as core objects of pedagogical activity, and we analyse doctoral students' experiences of the nature of these core objects. In our attempt to theorize doctoral students' experiences, our reference point is ethical theory, namely principle ethics.

Ethics is here operationalized as a set of five ethical principles, i.e., respect for autonomy, nonmaleficence, beneficence, justice and fidelity, which are commonly applied in ethical guidelines for researchers (Kitchener 1985; 2000; cf. also analysis of European codes of conduct by Godecharle, Nemery, \& Dierickx, 2013). These ethical principles have been applied in another context of related nature, namely student affairs and mentoring (cf. Kitchener, 1985; 2000).

Respecting human dignity and the autonomy of the other party is a fundamental ethical principle (e.g., Kitchener, 1985; 2000; Welfel, 1998) in human relationships. In a supervisory setting, the first type of problem has to do with intrusion of a supervisor's views and values and to the narrowness of the perspectives allowed the student. This problem has been identified as a breach of respect for autonomy (Löfström \& Pyhältö, 2012). Imposing a supervisor's views and values on doctoral students' work, for instance, or accepting only a limited range of theoretical or methodological perspectives could become ethical problems if they compromise the students' opportunities to develop their research ideas and researcher identity. This is to be regarded as different from those situations in which students work on projects and are therefore constrained by choices made in the project at large. There can very well be support for development of students' own agency despite predefined premises (cf. also Lee, 2008). In collaborative projects, an individual may not always get his or her way, and compromises may be necessary. Negotiating aspects of research are part of learning to conduct research in a team, e.g. in co-authoring an article, and not a jeopardizing of students' autonomy. Supporting the doctoral students' autonomy does not entail that the student has complete choice regarding every aspect of research. Instead, by lack of autonomy is here meant 
situations in which the students' development into an independent researcher is seriously jeopardized due to unnecessary, non-negotiable and scientifically unjustified constraints on student choice and agency. Lack of autonomy has been identified to cause problems such as cynicism and experiences of inadequacy in early career academics (Vekkaila et al., 2012). By contrast, a supervisor's respect for a student's research decisions improves the student's ethical attitudes (Gray \& Jordan, 2012). Thus, lack of autonomy as an ethical problem could have adverse consequences for the integrity of the doctoral process.

Second, ethical problems may take the form of exploitation, abuse, dual relationships, and misappropriation of a student's work. These are typically the result of active decisions or circumstances that have outright detrimental effects on the students. Problems in this realm have been called breaches of non-maleficence, because there is typically a component of harm (Löfström \& Pyhältö, 2012). When doctoral students participate in research projects of the research community, they usually gain valuable work experience. However, problems and risk of breaching nonmaleficence may involve too heavy a workload causing experiences of exploitation, and unfair and harmful treatment. Individual differences in students' abilities to defend their "space" for doctoral study are likely to occur; while some student are able to take a position, others may find it more difficult to refuse tasks given by their superiors. Other problems reported are abuse, extensive exploitation, bullying, and harassment (Whitley \& Page, 2015) and racism (Truong, 2010). Still another problem involves dual relationships meaning emotionally and psychologically confounded supervisory connections, such as deep friendship, or therapeutic or intimate interactions (Goodyear, Crego, \& Johnston, 1992).

Third, ethical problems in supervision may be less explicit or dramatic than breaches of nonmaleficence, but nevertheless can be problems related to beneficence; in other words, the failure to do good can be problematic in the supervisory relationship. It has been suggested that this problem arises when a supervisor does not have the necessary competence to facilitate the doctoral study process or does not understand the supervisory role and its responsibilities (cf. Welfel, 1998). Beneficence can be compromised by not providing support to a student a supervisor has within his or her power to help, and when it would be reasonable to be supportive. Löfström and Pyhältö (2012) showed that the most common ethical issue faced by doctoral students was compromise of beneficence, including threats to student well-being. Although students' well-being was not explicitly threatened by their supervisors, the students felt that there was a lack of understanding on the part of the supervisor. Doctoral students may also experience difficulties in discussing personal issues that have an impact on their studies, such as matters related to family and relationships or 
health or economy. Doctoral students recognize that they needed moral support to preserve their psychological well-being, but may be unable to identify where to go in situations in which they feel uncomfortable approaching their supervisors (Löfström \& Pyhältö, 2014). Indeed, doctoral students have been found to experience high levels of stress in their studies (Anderson \& Swazey, 1998; Hyun et al., 2007; Kurtz-Costes, Helmke, \& Ülkü-Steiner, 2006). Students have also been shown to drop out of doctoral programs because of a lack of functional relationships with their supervisors and other academics in the scholarly community (Golde, 2005; Vekkaila et al., 2012). In one study, approximately one-third of doctoral students felt isolated from their academic communities or experienced their relationship to the community as problematic (Pyhältö Stubb, \& Lonka, 2009).

Fourth, in many social and professional contexts, obligations come with asymmetrical power relationships (e.g., Kitchener, 1985; Welfel, 1998; Wisker, 2012). Problems in supervisory relationships pertaining to misuse of power have been called breaches of justice (Kitchener, 1985). Prior studies (Löfström \& Pyhältö, 2014; 2015) have identified a set of problems pertaining either to misuse of that power or not recognizing the consequences for students of unequal power distribution: Problems were identified as arising from doctoral students' feelings of unfair treatment if a supervisor used power for the benefit of some students only or took advantage of students who have fewer abilities to fend for themselves. For instance, supervisors might claim ownership of data, research results, or article texts. Often, supervisors do have a stake in the doctoral students' research, and they may contribute in important ways, thus justifying ownership or authorship. However, there may be cases in which doctoral students feel that their limited chances to complain or object are taken advantage of in an unwarranted way, for instance, when a supervisor claims authorship simply because of seniority (Löfström \& Pyhältö, 2014; 2015).

Fifth, fidelity refers to keeping promises, being loyal, truthful, and respecting others (cf. Kitchener, 1985; 2000). Without fidelity, forming and sustaining relationships is impossible. The same goes for doctoral supervision. The supervisory relationship is based on the premise that doctoral students study and carry out research, while supervisors oversees and supports this process. If either party does not adhere to this premise, then it becomes difficult for the other party to maintain their part of the "promise." Ethical issues might arise from the failure of supervisors to fulfill their tasks. Such failures might occur through abandonment of a student or inadequate supervision. The latter has been shown to increase the risk of attrition (Pyhältö, Vekkaila, \& Keskinen, 2012). The analysis by Johnson, Lee and Green (2000) aptly illustrates a deeply-rooted view of supervision as supporting development of the independent scholar by practically neglecting supervision. Supervisors may embrace the notion that their role is to weed out the weaker students from the promising. Such a 
notion is problematic from an ethical perspective. However, even the availability of supervision may not always guarantee progress and a successful doctoral process (Lahenius \& Martinsuo, 2011).

Having identified ethical components of doctoral supervision, we set out to answer how these influence doctoral students' experiences of supervision and what might follow from those experiences. Prior research has shown that supervision contributes to degree completion and affects length-of-time to candidacy, student well-being and satisfaction with the doctoral experience as well as the competencies developed while studying (Meyer, Shanahan, \& Laugksch, 2005; Case, 2008; Pyhältö, Stubb, \& Tuomainen, 2011). Therefore, we have taken these variables as outcome indicators of supervisory ethics. We posed the following question: Do attributes of ethics in supervision predict positive experiences (engagement, satisfaction with supervision and with doctoral studies) or negative experiences (burnout, attrition intentions) in the doctoral experience, and if so, how?

\section{Methods}

\section{Context}

In Finland, doctoral programs revolve around a research project that accounts for approximately 75 percent of the total work for the degree. The student usually begins the research at the start of the program without previously having had extensive coursework. Subject and methodological courses in the behavioral sciences, including research ethics, account for 40 ECTS credits $(1$ credit in the European Credit Transfer System equals approximately 27 hours of study). Dissertations are either monographs or a compilation of three to five refereed journal articles, usually co-authored with the supervisors and sometimes with other senior researchers. In addition to the articles, the student writes a summary synthesizing the theoretical and methodological aspects and presents the findings described in the articles. Article compilation is the dominant form in Finland, with approximately two-thirds of dissertations in the behavioral sciences being article-based (Pyhältö, Stubb, \& Tuomainen, 2011). Article compilation dissertations are written almost solely in English, even though students are native Finnish or Swedish speakers. Doctoral students are required to have two named supervisors. This practice is in place to avoid situations of abandonment when a supervisor retires, moves to another institution or is for some other reason unable to supervise. One of the supervisors is the main supervisor, and the other a co-supervisor. Sometimes the main supervisor will be mostly responsible for the supervision, but often the two supervisors will supervise with equal contribution to the process. Doctoral students may consequently perceive having one or two main supervisors. The oversight takes place in supervisor -student dyads, triads or in research groups consisting of members at various levels and in different areas of expertise. Doctoral education is 
publicly funded and free. Costs of living are usually covered by personal grants, project funding, or wages earned by working outside the university. Supervisory training is provided for academics regardless of the length of their prior experience in this capacity or of the number of students they have already supervised. Participation in the training is highly recommended, but not compulsory. Supervision ethics is not an explicit topic in this module, but conversations during the trainings often converge on issues of ethical nature, i.e. how much to interfere in a students' writing process, and to what extent allow students' to make their own choices and consequently risk making mistakes.

\section{Participants}

The data were collected at two research-intensive universities in Finland, one large and one mediumsized. Both universities have an international profile, and both play important national and regional roles. The participants were 236 doctoral students: 127 from University 1 and 109 from University 2. All participants represented the behavioral sciences (including educational sciences, teacher education, psychology), and consisted of 183 women and 53 men. By and large, the doctoral students were in their thirties $(n=106)$, yet a large number were in their forties, fifties, and older $(n=97)$.

Those under the age of 30 were in the minority $(n=33)$. The sample is representative of the doctoral student population in the two universities in terms of the average age and gender distribution. In our previous research (Löfström \& Pyhältö, 2017), doctoral students in the behavioral sciences exhibited a wider range of ethical issues in supervision than their peers in natural sciences. With this in mind, it appeared reasonable to do the first quantitative study with the doctoral students in behavioral sciences in order to make sure that while the development of the survey instrument by default is geared towards data reduction, it does not do so disproportionally heavily.

Of the participants, 120 were full-time students and 109 were part-time. The participants were in different phases of their doctoral programs. Although the nominal study time for a doctoral degree in Finland is four years, completing the work is rarely achieved in that length of time, as reflected in the large number of students with more than four years of study in the sample. Forty-nine students were in their first or second year, 56 in their third or fourth year, and 49 were in their fifth or sixth year. Seventy-eight students had prolonged study careers with at least seven years of doctoral study behind them, and some had as many as 20 years as the study time has not been regulated until lately. Two-thirds of the students $(f=149)$ were in the process of writing a dissertation of the collected article type, while approximately one-third $(f=77)$ reported that they were writing a monograph. Only seven were undecided. 


\section{Ethical Issues}

Participation in the study was voluntary. Prospective students were informed of the purpose of the research. No identifying information was collected. No incentives were used. In Finland, an ethics review is required when research involves intervention in the physical integrity of research participants; deviates from the principle of informed consent; involves participants under the age of 15 being studied without parental consent; exposes participants to exceptionally strong stimuli; risks causing long-term mental harm beyond that encountered in normal life; or signifies a security risk to subjects (Finnish National Board on Research Integrity, 2009, 3). None of these conditions were fulfilled in this study. It is possible that survey items with statements on ethical issues are perceived as awkward, especially if a student has experiences of ethical challenges. On the other hand, the items were embedded in a broader survey including many different aspects of supervision experiences, and as such should not expose students to discomfort beyond everyday life experiences. On the contrary, students may find it comforting that their experiences are worth scientific inquiry that can lead to the improvement of current supervision practices.

\section{Data Collection}

Ethical Issues in Supervision Scales. This is a tool developed from a series of qualitative studies reported in Löfström and Pyhältö $(2012 ; 2014 ; 2015 ; 2017)$. The precise formulation of the items in the survey have been based on the doctoral student data (reported in Löfström \& Pyhältö, 2014; 2015, 2017). Working from within five ethical principles (cf. Kitchener, 1985; 2000) these studies identified the following themes:

1) Breaches of respect of autonomy: Intrusion of supervisor views, narrowness of perspectives

2) Breaches in non-maleficence: Exploitation and abuse, misappropriation, dual relationships

3) Breaches in beneficence: Not promoting well-being, not promoting a collective culture, lack of supervisor competence and failure to understand one's own role

4) Breaches of justice: Inequity, unfair ownership or authorship

5) Breaches of fidelity: Abandonment, inadequate supervision

Survey items were designed to reflect the above ethical breaches or problems. The items were formulated as statements that represented a stance on how the ethical aspect was experienced. Both positively- and negatively-worded items were included. The first set encompassed a total of 48 items, which were tried out in pilot tests with three doctoral students in the behavioral sciences. The number of items was narrowed to what we determined to be the minimal number of items to still be able create reliable scales. We thus settled for sixteen items reflecting the five ethical principles and the 
subcategories of exploitation, misappropriation, lack of collective culture, lack of well-being, supervisor competence, narrowness of perspective, intrusion of supervisor views and values, inadequate supervision, abandonment, inequality, and unfair authorship (cf. Table 1). While a lack of these problems or breaches may to a large extent resemble what could be coined as "good supervision," the qualitative studies help define how "good supervision" is tied to ethical aspects.

Doctoral Experience Survey. Scales measuring burnout (exhaustion, cynicism, and inadequacy, 11 items), and Engagement (energy, dedication, and absorption, 9 items) were included from the Doctoral Experience Survey (Pyhältö, Stubb, \& Tuomainen, 2011) validated in prior studies. The scales for Doctoral Student Burnout and Research Engagement have been developed by drawing on Schaufeli et al. (2002) and Maslach, Schaufeli, and Leiter (2001). The following are sample items from the burnout scales: "I feel overwhelmed by the workload of my doctoral research" (Exhaustion); "I feel like my doctoral dissertation is useless" (Cynicism); and "I used to have higher expectations of my doctoral research than I do now" (Inadequacy). The following are samples from the engagement scales: "When I conduct my doctoral research, I feel that I am bursting with energy" (Energy); "I find the doctoral research that I do full of meaning" (Dedication); and "When I am doing my doctoral research, I forget everything else around me" (Absorption). These items were measured utilizing Likert-type response scales ( 1 =fully disagree, $7=$ fully agree). Other items and their response alternatives from the Doctoral Experience Survey used in this study were items that help describe the circumstances around supervision from the doctoral students' perspective:

- Number of primary supervisors (one supervisor, two supervisors, no supervisor, other individual or entity)

- Group status (whether the student received supervision mainly individually, in a group, or both)

- Frequency of supervision (daily, weekly, once a month, once in two months, once in six months, less frequently)

- $\quad$ Satisfaction with a) doctoral studies, b) supervision $(1-7,1=$ very dissatisfied, $7=$ very satisfied $)$

- Have considered changing supervisor (yes / no)

- Actual change of supervision (yes / no)

- Attrition intentions (yes / no)

\section{Analyses}

Data were normally distributed, with skewness and kurtosis remaining within accepted values $( \pm 1$ and \pm 2 respectively). Statistical analyses included exploratory factor analysis, correlation (Pearson 2tailed), t-tests, univariate, and multivariate general linear models. Furthermore, simple linear 
stepwise regressions were used to predict positive and negative outcomes of the doctoral process based on experiences of ethical issues. To examine effect sizes, Cohen's $d, R^{2}$ and $\eta^{2}$ were used and interpreted according to the following: $\eta^{2}$ at $.01=$ small, $.06=$ medium, $.14=$ large effect sizes; and Cohen's $d$ at $.2=$ small, $.5=$ medium, and $.8=$ large effect sizes (Cohen, 1977; cf. also Stevens, 1996).

Varimax rotation with Kaiser normalization and Maximum Likelihood analysis were chosen for the factor analysis of the Ethical Issues in Supervision Scales. Missing values were replaced with series means. Sampling adequacy measures (Kaiser-Meyer-Olkin) showed that a sufficient amount of common variance existed among the variables (.87). Bartlett's test of Sphericity was significant (.000), indicating a non-identity matrix and verifying that proceeding with the current scales was acceptable. Solutions with different numbers of factors were explored, but a three-factor solution was theoretically the most meaningful (Table 1). Rotation converged in six iterations. The factors were called FORM $(\alpha=.71)$, RULE $(\alpha=.74)$, and CARE $(\alpha=.62)$. The eigenvalues of the three factors ranged between 1.33 and 5.36, and together explained 37 percent of the variance.

Communalities below .30 raised concern in six items. A closer examination of item-total statistics showed that deletion of one of these items substantially improved the reliability of the scales. This was a negatively-worded item loading on the CARE factor reflecting breaches of beneficence, more specifically, harming the well-being of doctoral students. It was removed and replaced with an item related to being able to discuss problems in the doctoral process openly with the supervisor taken from the experience scales in the Doctoral Experience Survey. The RULE factor was complemented with two items from the Doctoral Experience Survey: one on equal treatment (aligning with the principle of justice) and the other on the opportunity to treat problems constructively (aligning with the principle of beneficence). While this procedure may not be optimal, it showed the kinds of statements that would increase the reliability of the developed tool. The pilot test did not bring out these issues, but we see that the development of the tool is in its early phases an iterative process of analysis and refinement.

Table 1: Factor analysis of Ethical Issues in Supervision Scales with factor loadings.

\begin{tabular}{|c|c|c|c|}
\hline \multirow[t]{2}{*}{ Items } & \multicolumn{3}{|c|}{ Factors } \\
\hline & FORM & RULE & CARE \\
\hline I receive supervision when I need it. & .82 & & \\
\hline $\begin{array}{l}\text { I can negotiate about central choices regarding my dissertation with } \\
\text { my supervisors. }\end{array}$ & .72 & & \\
\hline
\end{tabular}


I have been left without supervision at some point during my doctoral $\quad-.44$

studies.

My supervisors encourage doctoral students to collaborate with each $\quad .43$

other.

My supervisors encourage me to explore alternative viewpoints in my $\quad .42$ research.

If my supervisors cannot advise me I am usually left without help.

My supervisors treat the doctoral students in a fair way. $-.39$

My supervisor favors some of the doctoral students. .74

My supervisors express critical comments on my research in a

friendly manner.

I feel that my supervisor has exploited my thoughts or products in an

unfair way.

The progress of my dissertation is hindered by the fact that my

supervisors make me do the work of others' in the research group.

My supervisors regard it important that everybody who is mentioned

as an author in an article or similar, actually has contributed

sufficiently.

I can tell my supervisor if a personal matter affects my work with the dissertation.

I have learned to hide viewpoints that differ from those of my

supervisors.

My dissertation reflects the choices of my supervisors rather than my own choices.

The FORM factor entailed six items of ethical principles of autonomy, beneficence, and fidelity. The common denominator was that all items reflected the research community, social relationships, and the way in which the structuring of supervision supported multi-voicedness and interaction. The RULE factor was comprised of eight items of the ethical principles of justice, non-maleficence, and fidelity. The common denominator was that all reflected fairness and adherence to rules as a means of ensuring equal treatment of doctoral students. The CARE factor included four items of ethical principles of autonomy and beneficence. The common denominator for these was a focus on personal relations and respecting the individual.

Sum variables were formed of the exhaustion, cynicism, and inadequacy sub-scales of the Burnout scale and energy, dedication, and absorption sub-scales of the Engagement Scale in the Doctoral Experience Survey.

\section{Results}

\section{Ethical Aspects and Model of Supervision}

Thirty-nine percent ( $f=93$ ) of the doctoral students reported receiving supervision mainly from one supervisor, fifty-nine percent from two supervisors $(f=139)$, and two percent $(f=4)$ reported not having a supervisor or receiving supervision primarily from another source than a named supervisor. 
There were no statistically significant differences (associated with small effect sizes) in perceptions of the ethics of supervision between the doctoral students, who received supervision primarily from one supervisor and students, who received supervision primarily from two supervisors (FORM $[t(230)=.11, p .>.05, d=.021], \operatorname{RULE}[t(230)=1.89, p .>.05, d=.257], \operatorname{CARE}[t(230)=1.08, p$. $>.05, d=.145]$.

Seventy-seven percent $(f=181)$ of the doctoral students reported working on their dissertation mainly on their own. Only ten students (4\%) reported working on their dissertation mainly as a member of a research group. Approximately one-fifth ( $\mathrm{f}=45 / 19 \%)$ reported that they worked as much on their own as they had as members of a research group. The students who worked mostly on their own, i.e., the majority, reported relatively low scores on their ethical experiences pertaining to the research community, social relations, and how the structuring of supervision supported multivoicedness and interaction (FORM). The students who mainly worked alone reported lower scores $(\mathrm{M}=4.390)$ compared to their peers, who had a balanced combination of both individual and team support $(M=4.82)$. The difference was statistically significant, although with a small effect size, $F(2,233)=3.93, p<.05, \eta^{2}=.033$.

Generally, students received supervision once a month $(f=72,31 \%)$. One-fifth of the students reported receiving supervision weekly $(f=47,20 \%)$ or daily $(f=3,1 \%)$. Almost half of the students received supervision once every two months $(f=43,19 \%)$, once every six months $(f=44,19 \%)$, or less frequently ( $\mathrm{f}=23,10 \%$ ). The frequency of supervision was related to how the students experienced ethics related to fairness $\left[\mathrm{FORM} F(5,227)=18.98, p<.000, \eta^{2}=.30\right]$, and adherence to rules in order to ensure equal treatment of doctoral students $\left[\operatorname{RULE} F(5,227)=7.38, p<.000, \eta^{2}=\right.$ .140]. This means that students who received supervision at least once a month were more positive about these ethical aspects of supervision. Those students who reported receiving supervision daily $(M=5.11)$, weekly $(M=4.86)$, or once a month $(M=4.92)$ differed statistically significantly on FORM from students who reported receiving supervision once in six months $(M=3.98)$ or less frequently $(M=3.36)$. Similarly, students who reported receiving supervision daily $(M=4.88)$, weekly $(M=4.90)$, or once a month $(M=5.00)$ differed statistically significantly on RULE from students who reported receiving supervision once in six months $(M=4.45)$ or less frequently $(M=$ 4.00). 


\section{Ethical Aspects and Satisfaction with Supervision and Doctoral Studies}

A smaller number of the students ( $f=25 / 11 \%$ ) reported having considered changing supervisors. These students also reported lower levels of experiences of ethicality for FORM (M = 3.93 vs. 4.71, $\mathrm{SD}=.94$ vs .85$)$, RULE ( $\mathrm{M}=4.33$ vs. $4.96, \mathrm{SD}=.72$ vs .77) and CARE (i.e., experiences of ethics pertaining to personal relations and respecting the individual $)(\mathrm{M}=4.29$ vs. $4.89, \mathrm{SD}=1.02$ vs .98$)$. The differences between those who had and those who had not considered changing their supervisor were statistically significant with medium to large effect sizes: FORM $t(122)=.-4.03, p<.000$, Cohen's $d=.877$, RULE $t(122)=.-3.68, p<.000$, Cohen's $d=.841$, and CARE $t(122)=.-2.73, p<$ .01 , Cohen's $d=.603$. For comparison, the 46 doctoral students who had de facto changed their main supervisor did not report lower levels on FORM, RULE, or CARE.

\section{Ethical Aspects as Predictors of Positive and Negative Outcomes of the Doctoral Process}

On average, the doctoral students were relatively satisfied with their supervision $(\mathrm{M}=5.35, \mathrm{SD}=$ $1.54)$ and with doctoral studies $(\mathrm{M}=4.58, \mathrm{SD}=1.31)$. They reported relatively high levels of energy $(\mathrm{M}=5.30, \mathrm{SD}=1.03)$, dedication $(\mathrm{M}=5.66, \mathrm{SD}=1.05)$, and absorption $(\mathrm{M}=5.03, \mathrm{SD}=1.25)$. They also reported moderate levels of exhaustion $(\mathrm{M}=3.19, \mathrm{SD}=1.41)$ and inadequacy $(\mathrm{M}=3.83$, $\mathrm{SD}=1.63)$ and fairly low levels of cynicism $(\mathrm{M}=2.26, \mathrm{SD}=1.37)$. Significant regression equations were found (Table 2). The ethics variables predicted both positive and negative outcome variables. CARE predicted all engagement variables, i.e., energy $F(1,232)=17.13, p<.000$, dedication $F(1$, $231)=12.76, \mathrm{p}<.05$, and absorption $\mathrm{F}(1,232)=4.50, \mathrm{p}<.05$. Effect sizes (Adj. $\mathrm{R}^{2}$ ) were, however, generally small (i.e. .07, .09, and .02, respectively). FORM predicted dedication $\mathrm{F}(1,231)=12.76$, $\mathrm{p}$ $<.01$. All ethics variables predicted satisfaction with supervision: $\operatorname{FORM~F}(1,227)=134.55, \mathrm{p}<$ $.000, \operatorname{RULE~F}(1,227)=134.55, \mathrm{p}<.000$, and CARE $\mathrm{F}(1,227)=134.55, \mathrm{p}<.05$. Effect sizes $($ Adj. $\left.\mathrm{R}^{2}=.64\right)$ can be considered large. In addition, FORM F $(1,231)=45.33, \mathrm{p}<.000$ and RULE F(1, $231)=45.33, \mathrm{p}<.000$ predicted satisfaction with doctoral studies (effect sizes, Adj. $\mathrm{R}^{2}=.28$, were mediocre).

FORM predicted cynicism $(\mathrm{F}(1,232)=32.61, \mathrm{p}<.000$, and FORM and CARE predicted feelings of inadequacy $(\mathrm{F}(2,231)=10.99, \mathrm{p}<.000$. RULE predicted attrition intentions $(\mathrm{F}(1,226)=12.46, \mathrm{p}<$ .01 , and exhaustion $\left(\mathrm{F}(1,232)=7.98, \mathrm{p}<.01\right.$. Effect sizes were, however, generally small $\left(\right.$ Adj. $\mathrm{R}^{2}=$ $.03-.09)$.

Table 2: Summary of simple linear regression analyses for ethics variables predicting positive (+) and negative $(-)$ outcomes in the doctoral process $(\mathrm{N}=235)$. 
Table 2: Summary of simple linear regression analyses for ethics variables predicting positive (+) and negative (-) outcomes in the doctoral process $(\mathrm{N}=235)$.

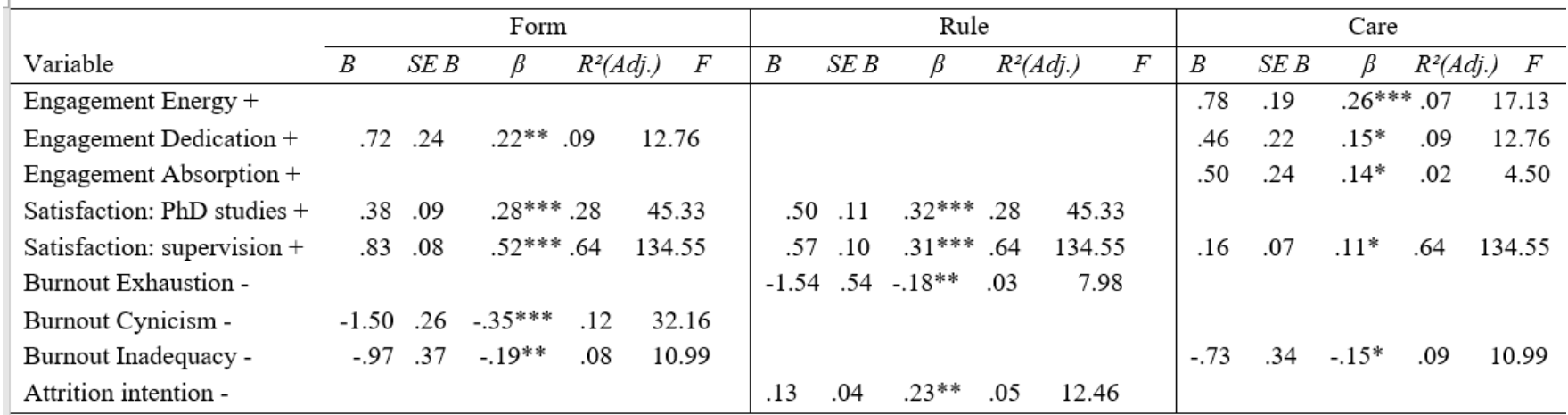

$$
{ }^{*} R \leq .05 .{ }^{* *} p<.01 .{ }^{* * *} p<.000
$$

\section{Discussion}

The study showed that ethical aspects of supervision matter in both positive and negative outcomes of the doctoral process, including engagement, satisfaction with doctoral studies and supervision, as well as burnout and attrition intentions. The five ethical principles were structured into three core, ethical entities in the doctoral students' experiences of the supervision, namely, 1) the research community and the supervisory structure (FORM), 2) fairness and adherence to rules that ensure the equal treatment of doctoral students (RULE), and 3) respectful relationships (CARE). We may conclude that the ethical aspects in supervision, as structured along the lines of ethical principles, align with theoretical understanding of supervision pedagogy, namely 1) supervision as facilitation of socialisation into the research community (Neumann, Parry, \& Becher, 2002; Parry, 2007), and 2) supervision as activity on different levels in the scholarly community (Pearson \& Brew, 2002; Pyhältö, Stubb, \& Lonka, 2009; Baker \& Lattuca, 2010; Stubb, 2012). These aspects appear to be vital in framing doctoral students' experiences of ethics in supervision, and demonstrate that the practices in doctoral supervision must be considered on a number of levels simultaneously, i.e., a macro/meso level (enabling infrastructures, rules, and regulations), a meso level (local practices of research communities), and a micro level (individual relationships).

The supervisory model was related to the doctoral students' experiences of its ethical aspects, which favored multi-voiced oversight and social interaction. The result is in line with research that speaks for a multilevel shared practice in which various agents assume supervisory activities and responsibilities (e.g., Dysthe, Samara, \& Westrheim, 2006; Pyhältö, Stubb, \& Lonka, 2009; Wisker, 2012; Vehviläinen \& Löfström, 2016). While supervisors do play an important role in the process, other scholars as well as fellow doctoral students can serve the purposes of guiding and scaffolding. In our context it appears that doctoral students' experiences of the ethics of supervision is defined 
through other aspects of supervisor than the supervisory arrangement in terms of how many primary supervisors the student has. This may be due to the fact that having two supervisors is a relatively common practice making good co-supervision practices a necessity for "supervisory survival". In another context, co-supervision may emerge as a regulator of the doctoral students' experiences of the ethics of supervision, but establishing any relationship requires further research. For instance, Catherine Manathunga (2012) has explored team supervision through emergence of power. Power struggles between supervisors could result in ethical challenges in the doctoral students' experience of supervision.

As shown by prior research, frequency of supervision is an important regulator in the doctoral process (Pyhältö, Vekkaila, \& Keskinen, 2015). Frequent supervision contacts enables questions to be discussed as they appear, rather than allowing emerging issues to remain undiscussed and eventually escalate to ethical problems. As shown by these authors, regular meetings between the doctoral student and the supervisor facilitate a better student-supervisor fit through mutual negotiation and the building of shared meanings. This is likely to facilitate also a better fit" between the student and supervisor in terms of ethics and conceptions thereof.

There may be underlying features in the supervision context, which are related to doctoral students' experiences of the ethics in latent ways. Infrequent supervision may be an indication of a problem, either as the infrequent supervision being the cause of it, or the infrequency being the result of some underlying issue. Ethical aspects of supervision were related to considerations of changing supervisors, but without acting on the idea. Students who consider changing their supervisors may worry about taking up the issue, and as long as they themselves or others in their research community do not react, problems are likely to persist. Considering that doctoral supervision has tended to be the most private of university teaching-learning contexts (Johnson et al., 2000), the above situation is a potential growing ground for ethical problems. At the same time, considerations of changing and actually changing supervisor can occur for a number of reasons, which may not as such involve ethical issues (e.g. retirement of supervisor, supervisor changing university, student changing topic).

The study showed that doctoral students' experiences of ethical issues in supervision were related to positive outcomes, i.e., engagement and satisfaction with doctoral studies and supervision, as well as to negative outcomes, i.e., burnout and attrition intentions. High ethical standards and practices in doctoral supervision are thus both a prerequisite of the supervisory relationship and also factors that contribute to the supervisory process. However, experiences of the various manifestations of ethics 
contributed in different ways. The relationship between experiences of ethical issues and the positive outcome variables suggests that, first, engagement is strengthened when supervisors make working for the benefit of their doctoral students a high priority and when individuals are appreciated and respected. Second, social relations in the research community and supervision that is structured to support multivoicedness and interaction together with fairness and equal treatment contributed to doctoral students' satisfaction with their supervision and studies. These findings point to autonomy and beneficence as essential components for engagement, while fidelity, justice, and nonmaleficence are vital for satisfaction.

The relationship between experiences of ethics and the negative outcome variables, i.e., burnout and attrition intentions, suggests that students' experiences of community and multivoicedness, fair treatment and equal application of rules, and respectful personal relationships form a baseline for the supervisory relationship. If a student's experience of these aspects is not constructive, negative consequences for well-being arise and increase the risk of attrition. These findings point to autonomy, beneficence, and fidelity as essential components for reducing the risk of burnout, while fidelity, justice, and non-maleficence are vital for preventing attrition among doctoral students. Accordingly, relatively high levels of burnout and attrition may be indicators of the importance of scrutinizing doctoral education practices and supervision from an ethical perspective within the research community. There could be issues, for instance, of supervision abandonment, exploitation or injustice, or infringement on autonomy brewing.

On the one hand, the presence of autonomy and beneficence in the supervisory relationship contributed to a positive outcome, that is, engagement, yet on the other hand, challenges experienced with these ethical issues contributed to negative outcomes, such as burnout. Research engagement and burnout are experiences in the affective domain (e.g., Appleton, Christenson, \& Furlong, 2008; Linnenbrink-Garcia, \& Pekrun, 2011). The results of our study suggest that positive experiences in the affective domain depend on a sense of self-determination and the belief that supervisors have the doctoral students' best interests at heart.

Simultaneously, the presence of fidelity, justice, and non-maleficence in the supervisory relationship also contributed to positive outcomes, namely, satisfaction with doctoral studies and supervision. In turn, a reduced sense of fidelity, justice, and non-maleficence in the supervisory relationship contributed to the negative outcome of attrition intentions. Whether or not to continue doctoral studies and satisfaction with different aspects of these studies (as operationalized in the present study) constitute the individual's assessment of the learning environment, in which the fit between 
a student's expectations and the environment are manifested. Positive experiences of the learning environment, meaning a good fit between the student and the educational surroundings, appeared to be affected by fairly tangible criteria of equal treatment, fair acknowledgment of individuals' work and contributions, availability of sufficient supervision, and clear boundaries for the supervisor's and the student's roles. Thus, ethical principles in the context of doctoral supervision contribute to the student's experience, and most importantly, they do so in different ways - some through an affective domain, some through the perceived learning environment (Figure 1).

Prior research has shown that both emotions and dynamics in the educational surroundings are important factors in the study experience. Emotions interact with student learning (Pekrun, Goetz, \& Frenzel, 2007), and experiences in the institution have implications for the doctoral student experience and process completion (Golde, 2005; Pyhältö, Vekkaila, \& Keskinen, 2012). Our study contributes to this knowledge base by identifying how ethical components might be related to affective experiences and experiences of the learning environment in the context of doctoral supervision. While prior research has shown that the dynamics between the student and the learning environment regulate engagement (Leech, 2012), this study adds understanding of how experiences of ethical aspects of supervision regulate the affective domain (e.g., the engagement) and the students' assessment of their learning environment.

Following the increased emphasis on quality assurance, increased participation in $\mathrm{PhD}$ studies, and move towards more programmed doctoral education in Nordic countries (Andres et al., 2015) attention must be paid to supervision as an integral part of doctoral education, and to supervisor competences and ability to support a variety of students. In doing so, it is necessary to understand supervision as an aspect of doctoral students' learning environment and their cognitive and affective experience of the doctoral process. This study provides input for the development of doctoral supervision by demonstrating how scrutinizing supervision through an ethical perspective can deepen our understanding of the dynamics between supervision and student experience. 


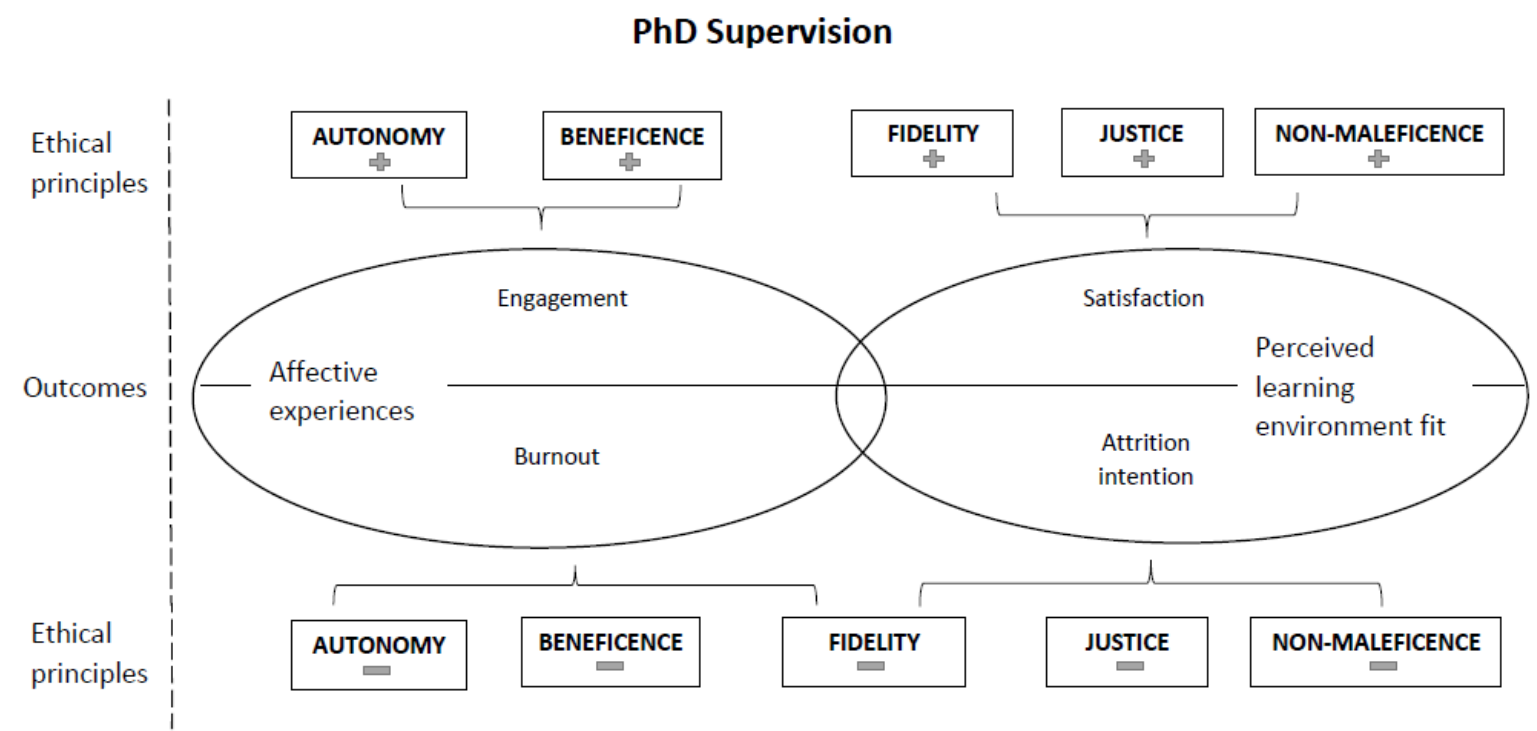

Figure 1: The contribution of ethical components in doctoral students' affective experiences and perceived learning environment fit.

This article has described the development of a novel tool, namely, the Ethical Issues in Supervision Scales, which can serve the needs of institutions that wish to measure the "ethical pulse" of their doctoral education and supervisory practices. This tool has been developed based on a series of qualitative studies with data from both doctoral students (Löfström \& Pyhältö, 2014) supervisors (Löfström \& Pyhältö, 2012) and both doctoral students and supervisors (Löfström \& Pyhältö, 2015; 2017) in which we were able to identify ethical issues related to five principles. Thus, the instrument is not developed only deductively working from the ethical principles, but basing the items on ways in which the principles emerged in the in-depth qualitative data. The fact that issues pertaining to the five ethical principles could be identified in both student and supervisor samples is in our view robust evidence for that we have identified a relevant construct and been able to operationalize it in a valid way. The tool adds to the limited selection of instruments in this domain, complementing the work of Gray and Jordan (2012) (whose survey instrument measures the relationship between student perceptions of their supervisors and student perceptions of academic integrity) and Anderson and Louis (1994) (whose survey instrument measures the graduate student experience and subscription to norms of science). The study describes the efforts in developing a tool specifically on doctoral students' experiences of supervision ethics as one aspect of high-quality doctoral supervision.

The regression analyses were suggestive of a number of causal relationships. The results warrant further research in other disciplines besides the behavioral sciences. As supervision paradigms are entrenched in disciplinary cultures (cf. Halse \& Bansel, 2012) studies will need to explore the extent 
to which differences in field and paradigm will be reflected in the doctoral students' experiences of the ethical aspects of their studies and supervision. Furthermore, we have used a principle ethics approach as the underpinning ethical theory of the tool. A next step might be to adopt a virtue ethics approach for the investigation of how doctoral students envision that ethical dilemmas and problems might be best dealt with and why so.

While the reliabilities of FORM and RULE were good or acceptable, the CARE scale had relatively low reliability and should thus be interpreted with caution at this point. Yet the analyses pointed to its potential relationships with the positive outcome variables in particular, which may be a relationship worth further exploration. Also the RULE items should be carefully considered as there were weaknesses in the initial set-up of items.

Further work is needed to develop the scales using samples from other populations, i.e., doctoral students in other fields. While quantitative tools by default are geared towards data reduction, and some of the complexity of the qualitative data is lost, we believe that the foundation of a set of qualitative studies underpinning the tool Ethical Issues in Supervision Scales provides it an apt content and a solid construction to be further refined.

\section{Acknowledgements}

The authors would like to thank Ms. Elisa Huotari for assistance with graphical representation, professor Susan Gardner for her feedback, and the anonymous reviewers for their comments on earlier versions of the manuscript. This work was supported by the Academy of Finland [grant number 252813] to the first author.

\section{References}

Alfredo, K., \& Hart, H. (2011). The university and the responsible conduct of research: Who is responsible for what? Science and Engineering Ethics, 17, 447-457.

Anderson, M. S., \& Louis, K. S. (1994). The graduate student experience and subscription to the norms of science. Research in Higher Education, 35(3), 273-299.

Anderson, M. S., \& Swazey, J. P. (1998). Reflections on the graduate student experience: An overview. New Directions for Higher Education, 10, 3-13.

Andres, L., Bengtsen, S. E., Gallego Castaño, L., Croussouard, B., Keefer, J., \& Pyhältö, K. (2015). Drivers and interpretations of doctoral education today: National comparisons. Frontline Learning Research, 3(3), 1-18.

Appleton, J. J., Christenson, S. L., \& Furlong, M. J. (2008). Student engagement with school: Critical conceptual and methodological issues of the construct. Psychology in Schools, 45(5), 369-386.

Baker, V. L., \& Lattuca, L. R. (2010). Developmental networks and learning: Toward an interdisciplinary perspective on identity development during doctoral study. Studies in Higher Education, 35(7), 807-827. 
Case, J. (2008). Alienation and engagement: Development of an alternative theoretical framework for understanding student learning. Higher Education, 55(3), 321-332.

Cohen, J. (1977). Statistical power analysis for the behavioral sciences. New York, NY: Academic Press.

Cornér, S., Löfström, E. \& Pyhältö, K. (2017). The relationship between doctoral students' perceptions of supervision and burnout. International Journal of Doctoral Studies, 12, 91-106.

Dysthe, O., Samara, A., \& Westrheim, K. (2006). Multivoiced supervision of Master's students: A case study of alternative supervision practices in higher education. Studies in Higher Education, 31(3), 299-318.

Finnish National Board on Research Integrity. (2009). Ethical principles of research in the humanities and social and behavioural sciences and proposals for ethical review. Helsinki. http://www.tenk.fi/sites/tenk.fi/files/ethicalprinciples.pdf. Accessed 29 June 2015.

Gardner, S. (2007). 'I heard it through the grapevine': Doctoral student socialization in chemistry and history. Higher Education, 54, 723-740.

Godecharle, S., Nemery, B., \& Dierickx, K. (2013). Guidance on research integrity: No union in Europe. Lancet, 381(9872), 1097-1098 + Appendix 6 p.

Godskesen, M. I. \& Kobayashi, S. (2016). Coaching doctoral students: a means to enhance progress and support self-organisation in doctoral education. Studies in Continuing Education, 38(2), $145-161$.

Golde, C. M. (2005). The role of the department and discipline in doctoral student attrition: Lessons from four departments. Journal of Higher Education, 76(6), 669-700.

Goodyear, R. K., Crego, C. A., \& Johnston, M W. (1992). Ethical issues in the supervision of student research: A study of critical incidents. Professional Psychology: Research and Practice, 23(3), 203-210.

Gray, P. W., \& Jordan, S. R. (2012). Supervisors and academic integrity: Supervisors as exemplars and mentors. Journal of Academic Ethics, 10(4), 299-311.

Halse, C., \& Bansel, P. (2012). The learning alliance: Ethics in doctoral supervision. Oxford Review of Education, 38(4), 377-392.

Halse, C., \& Malfroy, J. (2010). Retheorizing doctoral supervision as professional work. Studies in Higher Education, 35(1), 79-92.

Hyun, J., Quinn, B., Madon, T., \& Lustig, S. (2007). Mental health need, awareness, and use of counseling services among international graduate students. Journal of the American College of Health, 56(2), 109-118.

Johnson, L., Lee, A., \& Green, B. (2000). The PhD and the autonomous self: Gender, rationality and postgraduate pedagogy. Studies in Higher Education, 25(2), 135-147.

Jordan, S. R. (2013). Conceptual clarification and the task of improving research on academic ethics. Journal of Academic Ethics, 11(3), 243-256.

Kiley, M., \& Mullins, G. (2005). Supervisors' conceptions of research: What are they? Scandinavian Journal of Educational Research, 49(3), 245-262.

Kitchener, K. S. (1985). Ethical principles and ethical decisions in student affairs. In H. J. Canon \& R. D. Brown (Eds.), New directions for student services: Applied ethics in student services (pp. 17-29). San Francisco: Jossey-Bass.

Kitchener, K. S. (2000). Foundations of ethical practice, research, and teaching in psychology. Lawrence Erlbaum.

Kobayashi, S., Berge, M., Grout, B. W. W., \& Rump, C. Ø. (2017). Experiencing variation: learning opportunities in doctoral supervision. Instructional Science, 45, 805-826.

Kurtz-Costes, B., Helmke, A. L., \& Ülkü-Steiner, B. (2006). Gender and doctoral studies: The perceptions of PhD students in an American university. Gender \& Education, 18(2), 137-155.

Lahenius, K., \& Martinsuo, M. (2011). Different types of doctoral study processes. Scandinavian Journal of Educational Research, 55(6), 609-623.

Lee, A. (2008). How are doctoral students supervised? Concepts of doctoral research supervision. Studies in Higher Education, 33(3), 267-281. 
Lee, A., \& Williams, C. (1999). "Forged in fire". Narratives of trauma in PhD supervision pedagogy. Southern Review, 32(1), 6-26.

Leech, N. L. (2012). Educating knowledgeable and skilled researchers in doctoral programs in schools of education: A new model. International Journal of Doctoral Studies, 7, 19-37.

Linnenbrink-Garcia, L., \& Pekrun, R. (2011). Students' emotions and academic engagement: Introduction to the special issue. Contemporary Educational Psychology, 36(1), 1-3.

Löfström, E., \& Pyhältö, K. (2012). The supervisory relationship as an arena for ethical problemsolving. Education Research International, Article ID 961505. Accessed June 16, 2016 from http://www.hindawi.com/journals/edu/2012/961505/.

Löfström, E., \& Pyhältö, K. (2014). Ethical issues in doctoral supervision - The perspectives of PhD students in the natural and behavioural sciences. Ethics \& Behavior, 24(3), 195-214.

Löfström, E., \& Pyhältö, K. (2015). "I don't even have time to be their friend!" Ethical dilemmas in $\mathrm{PhD}$ supervision in hard sciences. International Journal of Science Education, 37(16), 27212739.

Löfström, E. \& Pyhältö, K. (2017). Ethics in the supervisory relationship: Supervisors' and doctoral students' dilemmas in the natural and behavioural sciences. Studies in Higher Education, 42(2), 232-247.

Mahmud, S., \& Bretag, T. (2013). Postgraduate research students and academic integrity: 'It's about good research training'. Journal of Higher Education Policy and Management, 35(4), 432-443. Manathunga, C. (2012). Supervisors watching supervisors: The deconstructive possibilities and tensions of team supervision. Australian Universities' Review, 54(1), 29-37.

Maslach, C., Schaufeli, W. B., \& Leiter, M. P. (2001). Job burnout. Annual Review of Psychology, 52(1), 397-422.

Meyer, J. H. F., Shanahan, M. P., \& Laugksch, R. C. (2005). Students' conceptions of research. I: A qualitative and quantitative analysis. Scandinavian Journal of Educational Research, 49(3), 225-244.

Neumann, R., Parry, S., \& Becher, T. (2002). Teaching and learning in their disciplinary context: A conceptual analysis. Studies in Higher Education, 27(4), 405-417.

Parry, S. (2007). Disciplines and doctorates. Dordrecht: Springer.

Pearson, M., \& Brew, A. (2002). Research training and supervision development. Studies in Higher Education, 27(2), 135-150.

Pekrun, R., Goetz, T., \& Frenzel, A. C. (2007). Perceived learning environment and students' emotional experiences: A multilevel analysis of mathematics classrooms. Learning and Instruction, 17(5), 478-493.

Protivnak, J. J., \& Foss, L. L. (2009). An exploration of themes that influence the counselor education doctoral student experience. Counselor Education \& Supervision, 48, 239-256.

Pyhältö, K., Stubb, J., \& Lonka, K. (2009). Developing scholarly communities as learning environments for doctoral students. International Journal for Academic Development, 14(3), 221-232.

Pyhältö, K., Stubb, J., \& Tuomainen, J. (2011). International evaluation of research and doctoral education at the University of Helsinki - To the top and out to society. Summary report on doctoral students' and principal investigators' doctoral training experiences. University of Helsinki. Accessed February 21, 2016 http://wiki.helsinki.fi/display/evaluation2011/Survey+on+doctoral+training.

Pyhältö, K., Vekkaila, J., \& Keskinen, J. (2012). Exploring the fit between doctoral students' and supervisors' perceptions of resources and challenges vis-á-vis the doctoral journey. International Journal of Doctoral Studies, 7, 395-414.

Pyhältö, K., Vekkaila, J., \& Keskinen, J. (2015). Fit matters in the supervisory relationship: Doctoral students and supervisors perceptions about the supervisory activities. Innovations in Education and Teaching International, 52(1), 4-16. 
Schaufeli, W. B., Martinez, I., Pinto, A. M., Salanova, M., \& Bakker, A. (2002). Burnout and engagement in university students: A cross-national study. Journal of Cross-Cultural Psychology, 33(5), 464-481.

Stevens, J. (1996). Applied multivariate statistics for the social sciences ( $3^{\text {rd }}$ ed.). Mahwah, NJ: Lawrence Erlbaum.

Stubb, J. (2012). Becoming a scholar. The dynamic interaction between the doctoral student and the scholarly community. Research Report 336. Department of Teacher Education, Faculty of Behavioural Sciences, University of Helsinki.

True, G., Alexander, L. B., \& Richman, K. A. (2011). Misbehaviors of front-line research personnel and the integrity of community-based research. Journal of Empirical Research on Human Research Ethics, 6, 3-12.

Truong, K. (2010). Racism and racial trauma in doctoral study: How students of colour experience and negotiate the political complexities of racist encounters. Doctoral dissertation. University of Pennsylvania.

Vehviläinen, S., \& Löfström, E. (2016). 'I wish I had a crystal ball': Discourses and potentials for developing academic supervising. Studies in Higher Education, 41(3), 505-524.

Vekkaila, J., Pyhältö, K., Hakkarainen, K., Keskinen, J. \& Lonka, K. (2012). Doctoral students' key learning experiences in the natural sciences. International Journal for Researcher Development, 3(2), 154-183.

Welfel, E. R. (1998). Ethics in counceling and psychotherapy: Standards, research, and emerging issues. Pacific Grove, CA: Brooks/Cole.

Whitley, L., \& Page, T. (2015). Sexism at the centre: Locating the problem of sexual harassment. New Formations, 86, 34-53.

Wisker, G. (2012). The good supervisor: Supervising postgraduate and undergraduate research for doctoral theses and dissertations ( $2^{\text {nd }}$ ed.). New York: Palgrave Macmillan. 